\title{
Vahid Online: Post-2009 Iran and the Politics of Citizen Media Convergence
}

\author{
Babak Rahimi \\ Program for the Study of Religion, Department of Literature, University of California, San Diego, \\ 9500 Gilman Dr, La Jolla, CA 92093, USA; brahimi@ucsd.edu \\ Academic Editor: Terri Towner \\ Received: 3 September 2016; Accepted: 18 November 2016; Published: 30 November 2016
}

\begin{abstract}
An attempt is made to study the social network site, Vahid Online, pseudonym of a leading Iranian activist who has the largest social media followership online. Vahid Online is Iran's leading distributor of information about social and political news about Iran, a source of information used by citizens and journalists. Similar to Twitter, Vahid Online posts, shares, and communicates news in short messages with hyperlinks, hashtags, or internet slang for multimedia purposes. In this networking media space, citizen journalism is assumed the civic responsibility of news and information dissemination with a perceived conception of internet as an agency of change. Vahid Online, I argue, is representative of an individuated networking activism in the new technology for information production. Technology, likewise, is imagined as a political agency and, in turn, citizenship is redefined through technology that carries the promise of change. It is also argued that Vahid Online's conception of citizen journalism is directly born out of the Green Movement in 2009, a protest movement against the 2009 presidential elections with a self-image of networked citizenship with a relative reliance on a weak tie model of civic association. The notion of citizen journalism examined here is one of civic participatory activism in archiving the collection, reporting, and dissemination of news through the merging of diverse media technologies in an attempt to create and distribute the most impact spreading news. The paper finally offers a critical analysis and argues that Vahid Online is more about individuated network framing of a privileged politics through practice of new technology.
\end{abstract}

Keywords: citizen journalism; internet activism; media convergence; journalism; Iran

\section{Introduction}

In the wake of the Zapatista movement's use of Web in the 1994 uprising, studies of social movements and their intersection with the internet flourished as scholars turned to the way online political activism can shape new forms of dissent [1]. Seen through complex symbols, rhetoric, repertoires, and communicative practices, online activism was perceived as less dependent on hierarchical organizations and centralized control by elites in redefining politics, and yet entwined with new conceptions of self and collective action. At the heart of online activism lay the ability of individuals and organizations to disseminate, organize, and creatively engage in contentious politics staged in mediated ways.

Whether considering movements such as the Occupy Movement and Black Lives Matter in the U.S., or the Arab Spring in Tunisia or Egypt, social movements across the globe increasingly push for new forms of action through multi-media platforms with internet and its cultural networked characteristics providing an alternative medium of activism. The media landscape referenced here is one of disruption, couched in the transgressive discourse of "sequence of revolutions" which evokes something inherently transformative about the new technology [2]. In the context of late modernity, 
the transformative dimension is the greater ability to have control over exchange, production, and consumption of information to interact with intensifying global patterns of interconnectivity.

In such an increasingly networked political sphere where citizens confront risk and uncertainty of the nation-state in respect to shifting transnational ties, the internet opens up opportunities to make, and also undo, radical changes, changes that have become manifest in the formation of new social relations online [3]. Yet despite perceived opportunities, the effective reach of online activism toward political change remains a contentious topic. As politically engaged activists employ online strategies for various contentious activities, it remains unclear the extent to which the new technology changes forms of activism that redefine politics.

With the aim of rethinking online activism, this study adopts a case study approach with a focus on Vahid Online, an Iranian online activist site operative in new media space, in particular, social media and mobile apps where dissident discourse is bypassed by gatekeepers and proliferated through networked connectivity. Vahid Online is a pseudonym of a leading Iranian online activist who has the largest social media followership online. A "People's Choice Winner" and described by the Bobs (Deutsche Welle awards) as a leading online activist to follow, Vahid Online is one of Iran's leading distributors of information about social and political news about Iran, and, similar to Twitter, a source of information used by citizens and journalists in producing an "ambient" news site of open source nature [4].

Such media space has relied on a perception of citizen journalism that involves the civic task of dissemination of news and information with the view of the internet as an agency of change. The case of Vahid Online identifies an individuated networking embedded in the new technology for information dissemination and production. Yet such networking is ultimately about how the new technology is perceived and reenacted through political activism. While for Vahid Online technology is imagined as a political agency, citizenship, in turn, is redefined through the very technology that carries the promise of change. Part of my interest in Vahid Online, in this sense, lies in a conception of citizen journalism that is directly born out of the Green Movement in 2009, a protest movement against the 2009 presidential elections, with a self-image of a networked citizenship that is essentially based on a weak tie model of civic association. The type of citizenship advanced is one of total engagement by which interaction between political activist and the internet produces an alternative civic engagement.

The alternative activism can be characterized as user-generated political discourse. As in the case of Vahid Online, such political discourses revolve around the notion of citizen journalism of civic participatory activism in the archiving, collection, reporting, and dissemination of news through the merging of diverse media technologies in an attempt to create and distribute the most impact spreading news. The interlinking of media, I suggest, serves as a new model of online activism, a conception that involves, in part, the convergence of old and new media contents and modes of communication marked by multifaceted media experiences. Equally important is the notion that the converged media space signifies a new conception of citizenship to disrupt politics as an order of hierarchy and as a closed system.

However, this paper also argues that social imaginary of technological activism of Vahid Online is less about convergence and more about individuated framing of politics through rhetoric of new technology. By individuated framing I refer to organization and customization of information on media outlet ostensibly perceived as an individual effort in producing content. While inherently networked, framing of individuated practices carry an exclusionary political agenda with selectivity of news for distinct audiences aimed to entertain with a political agenda. Here, the observation of exclusionary politics of Vahid Online is made in terms of ways in which online activism carves out a social space to accommodate specific audiences who are partly producers of news, information, and ideas that the social media site relies on. The convergence process therefore includes not only technology, but also networks of consumers and producers, as "audience," who self-define online activism in its social media forms as a source of civic action and political change. 
The case study analysis here primarily relies on the method of netnography, online ethnographic research based on content, textual and visual analysis of network communication [5]. The process of gathering online content as cultural data includes the study of ways of sharing and spreading information, stories, news, gossip, and jokes within connected networks. The ethnographic study of online connections also encompasses the study of changing discourses, rituals, styles of self-representation, symbols, and performances that suggest social practices of multiple trajectories. Netnography, in a short description, therefore includes the study of ways in which individual users experience online practices and articulate them through technologies they seek to redefine themselves. In this study, my focus is not only on a particular (social or app) site, Vahid Online, but complex communicative practices that carry the political ideal of change through the technological practice of social networking.

In what follows I first provide a theoretical discussion on the idea of citizen media convergence. The following discussion will consider the 2009 post-election Iranian context and the emergence of Vahid Online as a result of transnational online activism. My discussion on Vahid Online in the final section of this study revolves around transnational connections in diaspora form, and also the contours of convergence culture on multiple media outlets that identify the popular social media site in terms of civic politics of an alternative type.

\section{Citizen Media Convergence}

The intersection of politics and internet as a form of media has been a focus of scholarly research with contentious debates on how actors shape politics through technology-enabled communication. A key topic of debate has been the extent to which political actors online can construct new forms of political activism by forging campaigns, asserting collective claims, and influencing public opinion by shaping "offline" political activism [6-15]. Significant in the ongoing-debate, in broad terms, has been the relationship between politics and technology, and the extent to which activism has undergone change with such complex relations.

While studies show various impacts and typologies of activism based on specific contexts, the notion of social media as a form of political activism carries assumptions about activism and the nature of politics, and ways in which new technologies such as the internet can be appropriated by social movements to change power relations. Assumptions about technology are primarily regarding perceptions about the relationship between political action and the means of communication that can articulate action in the political sphere. Such perceptions then in turn become evident in internet activism, implemented in varied political contexts as power dynamics switch in degree and intensity. Political setting, therefore, is central to how politics is practiced in the digital sphere, as well as the ways in which online activism seeks to change such settings by reframing political discourse.

Central to online activism is what Manuel Castells has called "mass self-communication" or, as he defines, "the use of the Internet and wireless networks as platforms of digital communication." [16]. Communication in the form of many-to-many that entails the dynamic possibility of interconnectivity for political participation through multimedia platforms aimed at multiple audiences. The capillary of internet communication is inherently networked, and so is the political activism that organizationally, strategically, and communicatively operates through the internet for achieving political objectives, and such objectives are inherently conflicting and multidirectional. Online activists, in this networked sense, perform politics as bridge-makers and, in the case of prominent activists (in the words of Richard Davis, "agenda seekers"), actors who seek influence the broader political system and media landscape, and not necessarily attempt to achieve a total change [17].

Meanwhile, internet communication is not inherently about promotion of civic politics of democratic discourse. Numerous studies have shown that the internet's many-to-many dynamics can also be a source of polarization, exclusion, and collapse of political discourse in the formation of what Cass Suntein has famously called "cyber-balkanization" [18]. In nodes of communication networks, users, in particular, committed political activists online, interact through a "filter bubble" —in particular, 
social media sites and search engines such as Google, customized to personalized filters wherein actors communicate in self-enclosed networks, linking like-minded individuals [19]. In the age of algorithms and data-driven digital capitalism, it is hard to identify the internet as a horizontal and free space of communication while digital communication increasingly resembles offline civic discourse to mobilize not deliberative but partisan politics.

In light of the complex relationship between citizenry and state discourse, what is distinct about political discourse on the internet is the very mode of communication that has signified the new technology as a network of networks. Rather than emerging as "new media," digital communication is inherently networked, marked by complex intertwining, though not always cooperative, ties and nodes in the production of what Henry Jenkins's has famously described as "convergence culture", a complex set of flow and spread of information through multiple platforms converging through consumers and producers of media [20]. The spread in the digitization of media has not only transformed communication industries and services, but also ways of doing politics in terms of wide access, use, and spread of information in the overlapping practices of old and new media technologies. Media convergence identifies a diverse array of media consumption and production as providing linkages for user connectivity across time and space.

Notwithstanding the idealist roots of internet technology, the ideals and value, grounded in what Guboin Yang, following Ernst Bloch, has described as the "utopian impulse" of new citizen activism, are reinvented in the emerging digital sphere of (multi) media convergence ([6], pp. 155-56). New collective actions operate in individuated networked ways, which, accordingly, reflect new forms of politics born out of media convergence practices. In this new media landscape, every political actor as "user" becomes a source of information, reporter of news, and disseminator of ideas. The new notion of citizenship, as "citizen media convergence," therefore carries the social imaginary of digital technology as essential to political activism for lowering obstacles in "face-face" political settings for alternative civic participation.

The conception of "alternative" here marks an idealization of activism that goes beyond politics as usual by using the new technology for alternate political activity. Such conception also assumes a notion of political action in terms of voluntary participation, creativity of technological appropriation, and formation of online communities in enhancing opportunities in performing politics for a better world. The utopian impulse is colored by how political action can be performed through appropriated technologies in the construction of a different form of politics. Under conditions of contentious politics associated with perceived state power, internet is more than a "strategic platform" for mobilization and organization of collective action, but an interconnective space of alternative political action conceptualized on the notion of participatory networks.

\section{3. "Every Citizen Is a Media Outlet"}

Politics, Otto von Bismark famously declared, is the art of possible; and one could add, when faced with the perils of a political crisis it becomes the art of making the impossible possible. Utopian aspiration, which mostly becomes manifest at moments of crisis, ensures the emergence of alternative politics to reconstruct the political order. With crisis comes despair, caused by an apparent political breakdown, but also hope through breakthroughs for new possibilities, tactics of resistance, and ultimately different forms of political order. It is amid such crises that alternative forms of political action such as online activism become more visible.

The June 12th Iranian presidential elections marked a historic political crisis in the Islamic Republic since its inception in 1979. The proliferation of a new protest movement was sparked in reaction to the official declared victory of Mahmoud Ahmadinejad as the incumbent president. In terms of voter turnout, the 2009 elections were one of the most participated in the history of Shi'i Islamist polity with some 80 percent of the 46 million eligible voters having participated [21]. The elections also saw innovative pre-electoral campaigns that brought what Afsaneh Kalantary has called "spirit of Carnival" with heightened symbols of radical change couched in the performance of electoral 
politics [22]. The elections were also the most polarizing in the country's electoral politics, which brought about a realignment of political factions and, more importantly, the emergence of a protest movement that came to define the post-election period.

The end of Mahmood Ahmadinejad's first term in 2009 coincided with important changes in economic conditions and political alliances with conservative factions, including pragmatists, steadily in tension over the populist politics of Ahmadinejad. With Reformists determined to achieve an electoral come back, and a disgruntled middle-class segment of the population increasingly anticipating the pre-electoral season, the 2009 elections were bound to be historic. The combination of failed policies from the administration in power led by a hardliner faction and backed by the Supreme Leader, Ayatollah Ali Khamenei, and an electorate divided over politics laid the basis for a contentious election.

The landslide re-election of the incumbent President saw a swift reaction from opposition groups, who charged electoral irregularities. The leading reformist figure, Mir-Hussein Mousavi, who had declared himself a winner before the election results were officially announced, called his supporters to take to the streets to protest the results. What followed after the elections was the transfiguration of an electoral campaign, comprised of a diverse range of social groups, but mostly middle-class Iranians, into a social movement that would change Iranian politics.

The change came on both electoral and political cultural levels. Elections in the Islamic Republic are under the supervision and approval of the Guardian Council, a body of appointed (male) jurists responsible for interpreting the constitution and, more importantly, supervising elections and approving candidates running for public office, including the executive branch. The unelected institution wields influence in how elections are performed and who competes for votes. In historic terms, since the inception of the Islamic Republic and the institutionalization of theocratic order of the Velayat-e Faqih (Guardianship of the Jurist) in 1979, elections have served as the only limited democratic institutions within the Iranian state, despite their institutional limitations at the whim of the Guardian Council. As temporary instances of political openings during which competing candidates (though carefully selected by the regime) and their supporters can participate in the political process, elections have introduced the element of competition and relative openness of the political process. However, they have also always carried the risk of destabilization for the ruling elites.

The concern of political destabilization is particularly evident for the Supreme Leader, Ayatollah Ali Khamenei, whose strong support for political continuity has included the backing of hardliner candidates whose approval has been affirmed by the Guardian Council, which in turn has the support of the Supreme Leader. As the momentous victory of the reformist candidate, Mohammad Khatami, demonstrated in 1997, post-revolutionary Iranian elections entail the capacity to transform politics in ways that encourage the electorate to seek change within the political system, if only done with a massive participatory force [23].

The 2009 election revealed a deep tension with the approved choice of candidates, as Mousavi and Mehdi Karoubi, a lesser popular reformist cleric and a former Speaker of the Parliament (1989-92; 2000-2004), respectively, vied for the office of presidency with Ahmadinejad, whose hardliner politics had shaped his period in office as the most controversial since the inception of the Islamic Republic in 1979. As early as April 2009, a new political culture emerged that quickly identified a dissident electoral campaign with claims over politics. Mousavi's supporters comprised a cross-section of the larger society, including artists, university students, intellectuals, middle-class professionals, (unemployed) workers, reformist religious associations, and women activists, whose enthusiastic support for reform characterized an electoral politics of change.

It was on the level of political culture that the campaign period redefined Iran's post-revolutionary politics. Capitalizing on the growing discontent, Mousavi's campaign began to organize an increasing number of rallies staged in stadiums or streets, which were characterized mostly with a newly made repertoire of signs, slogans, songs, symbols, and discourses. Mousavi supporters waved and wore green, a color that symbolically identified a new electoral politics, mostly known in its pre-election period as moj-e sabz or "the Green Wave". For the expanding campaign, the color green, associated 
with Iranian nationalism and Islam, served as a subtle but effective call for a new beginning. The Green camp felt a momentum, that its members were riding the crest of a powerful wave of history into a more democratic future; that Mousavi, in words of Scott Peterson, the American journalist covering the pre-election period, was the "promise of change that he embodied for his supporters, whether realistic or not" [24]. "The promise of change", in an important sense, identified a new paradigm of dissident activism in a new way of discoursing about politics, or in what Bernard E. Harcourt calls "a new grammar of politics" [25].

Such new grammar, first and foremost, entailed the horizontal conception of a leaderless movement to redefine post-Islamic Republic politics based on consensus and citizenship assembly. The Green Movement's new paradigm forged ahead a notion of citizenship that ultimately envisaged civic transformation of political life on the grass-roots level. Characteristically horizontal in organization, the Green Movement organized itself on perceived informal and decentralized networks, framed around political discourse of civic politics, and expanded into the digital sphere of activism. With allegation of electoral fraud after the elections, the Green Movement protesters engaged in a series of offline and online activist activities that changed the political landscape of the Islamic Republic. Hamid Dabashi calls this "a full-blown epistemic shift" in the Islamic Republic's political culture ([22], p. 59). Such "epistemic shift" is not just about a change in discourse, but an emergent dissident political movement self-generated through combined physical-urban and internet spaces. For the movement, the internet did not represent a mere tool of communication, but a new political space for making politics accountable and transparent, a collective site of action with roots in the introduction of internet in Iran in the mid-1990s [26].

The post-election period saw the Green Wave undergo a substantive transformation, as the electoral campaign spread into street-rooftop protests with street-rooftops as sites of demonstrations. Weeks following the elections, protesters engaged in collective action of contentious nature in the production and performance of protests with the use of multiple media outlets. Mousavi's description of the electoral campaign as "har Irani yek setad" (Every Iranian a campaign headquarter) evoked the idea of individuated participatory action embedded in campaigns designed for civic participation [27-29]. Through images, slogans, songs, and silent demonstrations that drew the media spotlight, the public protestations redefined the movement as an opposition current with new claims on the elections and, accordingly, state legitimacy. Media, in this performative sense, played a critical role.

"In the Green Movement, every citizen is a media outlet" Mousavi famously claimed [30]. The statement is a remarkable testimony to how the Green Movement activists constructed a self-image around the symbolics of media expressivity. "Every citizen" evokes a notion of politics that is ultimately based on dynamic political activism, a form of political citizenship based not on merely legal identity but participatory action on multiplicity of site with media as a major communicative medium. The metaphor of citizen as "media outlet" therefore highlights the vitality of citizen politics in the form of public opinion shaping mediated practice, recalling Marshall McCluhan's famous statement "the medium is the message", since media alters the way citizens not only communicate, but also view themselves with communicative image of mediated activism [31]. It is the medium, as the new ideal of citizenship as communication, which shapes and forms a new set of civic associations.

This communicative dimension with citizenship is particularly the case with the Green Movement and the use of Internet in the post-election period. The use of cellphones, social media, and personal computers in the days after the elections pushed for a street dissent politics that relied considerably on media, in particular, social media, to self-promote the movement across the world. However, the new media also facilitated a new way of framing activities by actors who increasingly viewed themselves, individually and collectively, as media outlets. Framing practices, especially in the case of the Green Movement, served as interpretive schemes to strategically produce counternarratives to established political perceptions [32,33]. In an important way, the very notion of "every citizen is a media outlet" serves as a framing-transformative marker in changing the self-perception of actors as political agencies of mediated form. 
The framing strategy of news covering the Green Movement protests by the protestors aimed at capturing the emotive and visual scope of the global and national public opinion. However, more importantly, the audio sound and visual imageries of the demonstrations helped energize the movement's ongoing attempts to challenge the state authority, prolonging contestation and ultimately undermining electoral results illegitimate. The framing practice of information gathering and distribution brought to the fore a set of rhetorical strategies that redefined the events unfolding based on symbolic repertoires in terms of adversity, justice, and a moral urgency. The postings and circulation of images, signs, and audio coverage of protests and police crackdowns online would facilitate emotive strategies of inciting public support and mobilization against the external other, namely the state. By extension, the distinguishing mark of circulation and sharing practices is the enactment of events, as framed through social media postings, display a potential for a global audience with a wide reach across regions. While targeting a national audience played a key role, the global factor signaled a new phase in the Green Movement in the post-election period, with diaspora protestors as key actors in the movement and its framing practices.

\section{Vahid Online and Post-Green Activism}

It is with the performative and diaspora dimension that Vahid Online emerged in the post-election period as a new form of political activism in post-election Iran. Run by a pseudonym of a leading Iranian activist in his 30s, a former engineer, Vahid Online is the most popular source of political information with the largest number of followers in Iranian social media. Vahid Online was an active member of Mousavi's 2009 campaign, reporting a government crackdown on an electoral headquarter in northeastern district of Tehran. It was at the Mousavi headquarters when, after attacked by security forces, Vahid Online posted the crackdown on social media, attracting a large audience, and hence beginning a citizen journalist career in the election period [34]. After his departure to Turkey and eventually setting down in the US, where he is currently settled on the east coast, Vahid Online became the most important source of news sharing for Iran-based users and beyond.

For Vahid Online the new phase of social media has marginalized the blogosphere, popular information sites for most Iranians in 2000s, because of the speed of information dissemination. It is in speed and the perpetual update culture that brought Vahid Online to the fore of Iranian media landscape in post-2009 period. With an active presence on microblogging Twitter, but mostly on the Russian-owned Telegram (a feature that will be discussed in the next section), Vahid Online has a seemingly perpetual presence online. It is the evocation of ubiquitous and pervasive connectivity that Vahid Online frames itself as a post-blogger activist. On his blog, where he nostalgically looks back on his blogging experience, he describes that a father wrote him how he has been a member of their family with the name "agha sorat" (Mr. Face), since his real name is unknown [35,36]. Another of his followers describes "Vahid Online" as "a single person media," which accentuates the notion of individuated networker, a lone activist who can never be offline; he only moves, as a follower explains on his blog, from one network to another by spreading news and information.

The rhetorical self-reference in terms of "Sharvand konjakave internet" (curious citizen of internet) and "khore khabare technology" (technology news worthy) emphasizes a selectivity of news gathering for public sharing, and yet the reference to "curious citizen" hints at an unlimited yearning for the acquisition of knowledge matched by the new technology that carries similar endless possibilities. The fusion of citizenship and technology as a medium of news production is central to Vahid Online. What it underlines is the blurring of consumer and producer of news in the construction of participatory citizenship as audience and journalist at once. Technology-enabled activism with claim on non-professionalism, as Vahid Online claims, also gives account of an ability to bypass editorial limitation, defying gatekeepers and pushing the flow of news through individuated networking online with significant impacts on offline domains.

A critical theme that Vahid Online has advocated is, as noted earlier, in what Jenkins's has famously described as "convergence culture". Though with limited access to all social media for Iranian 
internet users because of state filtering practices, Vahid Online exemplifies a form of convergence culture that relies on multiple media outlets, each of which relies on available news and shares the news with diverse audiences, and who also participate in the sharing culture and converging media practices.

In response to post-2009 elections, and in direct engagement with the 2013 presidential elections, which saw the victory of a pragmatist-reformist coalition led by Hasan Rouhani, Vahid Online has emerged as a unique social media platform for political and social activism. As discussed earlier, built around the ideology of citizen journalism, Vahid Online has combined several strategies to reshape post-2009 Iranian politics. Perhaps the most important strategy has been the sharing of information based on the assumption of a single embedded operator, embedded in multiple networks and modes of connections. The theme of sharing, and by extension circulation, advances the view that merging multiple media platforms by a single actor serves as a form of bridge-making in a transmedia landscape.

While sharing provides a range of exchanges in the form of information dissemination, affective support, or connectivity across both strong and weak ties, but mostly the latter, Vahid Online claims a distinct sharing feature. That is, information is selectively shared through computer-generated signs, symbols for further dispersion among multiple media platforms, in particular, in the social media domain, where Iranians based in Iran and diaspora have become increasingly active since 2009. In what can be described as "trans-sharing" Vahid Online has brought to the fore an interplay between digital and face-to-face politics, which became best pronounced in the 2013 presidential elections when the individuated social media site enabled the formation of shared spaces of interaction and connectivity for offline political activism.

The narrative form of Vahid Online is based on a set of sharing practices of multiple media contents that revolves around hashtag signs as framing markers of locative nature. For example, a hashtag for a pro-Rohani rally in Tehran posts a sign with photographic and textual content that invites a larger social media audience to virtually participate in the street rally as a collective experience based on weak social ties. Social media display of information is less about transmission, in this sense, and more about fostering affective bonds through distance connections. Using hashtags in social media postings carries the expressive sign of locating mediated events by cutting across time and space [37]. Normative context collapse as a form of activism seeks to reconfigure political landscapes by registering a new way of perceiving demonstrations. While hashtag culture seeks to influence face-to-face activism, the media use of hashtags has the potential to spread news through both weak and strong ties, where activists and passive observers could join forces, at a given time, to claim political change. As a form of digital activism, however, hashtags work as a form of counternarrative, a rhetorical sign tactic that seeks to make recognizable what is primarily ignored or purposely made silent in the mainstream media.

Such features of digital communication in its dissent form are matched by primarily a media convergence platform, modes of staging politics that are inherently multidirectional and permeable in content. The origins of the Vahid Online convergence can be traced back to the case of posting videos of the attack of security forces on the Mousavi headquarters in 2009. Once the film was posted by Vahid Online it first appeared on BBC Persia, and later on other TV and satellite media outlets, which picked up the images for global consumption. The speed of attacks by the security forces was matched by the swiftness in the spread of the news on social media and other media outlets. Similarly, during the 2013 elections, for example, Vahid Online posted hashtags, statements, comments, and shared news and information from social and mainstream media sites using multiple sites such as Instagram, Facebook, Twitter, YouTube, and, more importantly, Telegram. Vahid Online also appeared on non-Iranian press, such as New York Times, where his posts were reprinted online along with other Iranian activists' or journalists' Twitter and social media sites [38].

Vahid Online media convergence also involves the unique feature of reposting already available official and unofficial news, at times even rumors, primarily from social media sites, in particular, Twitter. With Telegram, the most popular instant messaging app in Iran, with 20 million users, 
Vahid Online has served as the main media hub for spreading social and political news deemed by the U.S.-based internet activist pertinent to an Iranian audience [39]. Unique with Telegram is its mobile application feature, which, unlike Facebook and Twitter, is not only unfiltered, but also represents one of fastest and, purportedly, secured messaging apps in the market. Telegram can also be used across social media platforms, in particular, by merging photographic, video, textual, and computer-generated signs like @ and hashtags, and emoticons which enables greater convergence of media content in multiple linguistic and networking ways. The Telegram media landscape is built around single account holders, but accounts can form minor and major online groups between friends, family, fans, followers, and news audiences.

However, more importantly, Telegram is inherently tied to mobile technology, as accounts are made possible through telephone numbers, registered to individual persons, and authenticated by SMS. The mobile device serves as an integral feature of Telegram as a mobile app, enhancing instantaneous information sharing through mobile interaction across time and space. Use of the mobile apps can be described as a convergence of the public and private spheres. The merging of the internet and mobile apps has enabled a photographic and video schematic change, and in ways information is increasingly and constantly becoming an online experience with individual actors engaged in networking operations for various purposes [40].

A key feature of Telegram mobile messaging that Vahid Online has relied on is what can be described as sharing compression. By this I refer to the use of mobile app messaging of Telegram to compress a select collection of information received, posted, circulated, and (re)shared on the messaging app. Vahid Online's Telegram account is most popular for selecting social and political news from the micro-blogging Twitter site, blurring the boundaries of news source and dissemination in ways that has reshaped Iranian social media. Sharing compression has two features: (1) the retrieving and posting of other social media users' statements, photos, videos, and news clips, some of which have been reclaimed from mainstream media but redesigned for social media setting; and (2) reframing information in a new networked collection of news, where the site in itself becomes a legitimate source of information. The sharing of news is less about recycling and more about representing information as alternative news, independent from mainstream news, although considerable news content of Vahid Online comes from mainstream news.

Vahid Online thrives on anonymity, but with a hint of paradox. The nameless activism here carries the assumption of privacy and yet the self-framing around namelessness entails a publicity of global reach. Vahid Online is visible as a source of information sharing and yet invisible as an activist with a distinct political agenda. The invisibility is a tactical move and yet it also reflects the diasporic distance that Vahid Online best exemplifies as a digital activist. The diasporic element enhances the convergence dimension with digital skills of internet activists such as Vahid Online becoming more pronounced in the experience of migration and change of identity in terms of fluidity and mobility of action across time and space. The identity change underscores the rhetoric and strategic activities of Vahid Online as a social mediated experience of mobility with transregional dimensions.

It is precisely the mentioned diasporic distance that also accentuates distinct exclusionary politics. By exclusionary politics I refer to the production of news through the social media platforms that are inherently designed on a selective scheme of news knowledge. How "news" is shared and circulated depends on the individuated politics of a single activist whose use of social media as a counternarrative platform not only selectively identifies news to be shared for a distinct audience, mostly a middle-class Iranian segment of the population, but also inserts an implicit self-ascribed sense of authenticity that would deflect such internet activism from the problem of manipulation, bias, and accountability, which journalism inherently faces.

The ideology of citizen journalism assumes a position of neutrality of not news sharing, but news content. However, sharing also entails a reproduction of news content by reframing the news in the process of online sharing with unintended consequences as the news spreads across the media landscape. The positioning factor also assumes privilege, as sites such as Vahid Online, 
by self-representation in terms of "curiosity" and "citizenship," downplay their social advantages in terms of gender, class, and differences of ethnicity.

The final question that one may propose in a critical analysis of Vahid Online is which citizen and for what audience does a sharing news platform promote in constructing a political conception of change with new technology playing an integral role in the process? The technological utopianism of citizen journalism assumes an equal access to the technology that will bring political change, and hence sustain internet activism as a distinct form of political action. However, with use of technology internet activism potentially excludes those "citizens," or otherwise known as "users," who do not have access to such technology. And if there is access, the digital skills of a privileged activist may not promote an inclusive participatory politics of civic interaction for those who do not have the skills, nor the social capital to acquire them.

\section{Conclusions}

In this study I have provided an analysis on complex, and at times contradictory, forms of self-presentation of an online activist that exemplifies performance of contention through technological practice of individuated network activism. Vahid Online produces a counternarrative of political dissent through the technology it relies upon as a discursive platform. However, in doing so, it also redefines activism in the converged media space of online communication where information resources and dissident visibility is generated for offline political impact.

Dissent visibility of Vahid Online raises new questions in the study of online activism. To what extend can multi-media activism in its converged formation change offline political context, in particular, in its authoritarian setting? While Vahid Online has been successful in spreading news, information, and dissident events, the popular social site has shown little impact beyond the middle-class segment of Iranian population based in urban centers. Moreover, even within its target audience, there is little evidence to suggest that, aside from the factor of internet celebrity status, it has shaped opinion independently from other media outlets, in particular, older news sites, primarily run by the state, where media convergence has had less of an impact in recent years.

Today, Vahid Online continues to enjoy a large followership with a segment of the Iranian population, especially diaspora communities. Its potential impact remains paramount in the upcoming elections as a source of information gathering and sharing. An empirical survey on Vahid Online in mapping of its complex network connectivity can be the basis of a follow up study in order to determine its social impact in terms of networking practices. However, the impact of the site primarily lies in the intersection of blogging and news sharing practices on mobile application sites, such as Telegram, and celebrity culture among a distinct segment of the Iranian population that views online activism as an alternative arena of political struggle. The political impact of Vahid Online, therefore, lies in its ability to bring together like-minded activists who also view and use the internet as a form of expressive politics beyond the control of state power.

This analysis has important implications regarding how online activism constructs politics based on a growing consciousness for self-expression. With the rhetorical use and incorporation of technology toward an inclusive politics, media convergent online activism involves an augmented reality that comprises audiences and participants in enclosed digital space, wherein news content becomes embedded in a changing market of social media consumption. Such news space is shaped by those who perceive themselves, as foremost, carriers of change in the era of late modernity, an era when consumption of information reifies news production as an ideological democratic good.

Conflicts of Interest: The author declares no conflict of interest.

\section{References}

1. Knudson, Jerry W. "Rebellion in Chiapas: Insurrection by Internet and public relations." Media, Culture $\mathcal{E}$ Society 20 (1998): 507-18. [CrossRef] 
2. Zysman, John, and Abrahm Newman. How Revolutionary Was the Digital Revolution? Stanford: Stanford University Press, 2007.

3. Rainie, Harrison, and Barry Wellman. Networked: The New Social Operating System. Cambridge: MIT Press, 2012.

4. Hermida, Alfred. "Twittering the news." Journalism Practice 4 (2010): 297-308. [CrossRef]

5. Kozinets, Robert V. Netnography: Doing Ethnographic Research Online. London and Thousand Oaks: Sage Publications, 2010.

6. Yang, Guobin. The Power of the Internet in China: Citizen Activism Online. New York: Columbia University Press, 2011.

7. Hill, Kevin. Cyberpolitics: Citizen Activism in the Age of the Internet. Lanham: Rowman \& Littlefield, 1998.

8. Kang, Jiyeon. Igniting the Internet: Youth and Activism in Postauthoritarian South Korea. Honolulu: University of Hawai'i Press, 2016.

9. Earl, Jennifer. Digitally Enabled Social Change: Activism in the Internet Age. Cambridge: MIT Press, 2011.

10. Castells, Manuel. Networks of Outrage and Hope: Social Movements in the Internet Age, 2nd ed. Cambridge and Malden: Polity Press, 2015.

11. Sobieraj, Sarah. Soundbitten: The Perils of Media-Centered Political Activism. New York: New York University Press, 2011.

12. Farris, David. Dissent and Revolution in Digital Age: Social Media, Blogging and Activism in Egypt. London: I.B. Tauris, 2013.

13. Karpf, David. The MoveOn Effect: The Unexpected Transformation of American Political Advocacy. New York: Oxford University Press, 2012.

14. Bennett, W. Lance. "Communicating Global Activism: Strengths and Vulnerabilities of Networked Politics." Information, Communication \& Society 6 (2003): 143-68. [CrossRef]

15. Christensen, Christian. "Discourse of Technology and Liberation: State Aid to Net Activists in an Era of 'Twitter Revolutions'." The Communication Review 14 (2011): 233-53. [CrossRef]

16. Castells, Manuel. Networks of Outrage and Hope: Social Movements in the Internet Age, 1st ed. Cambridge: Polity Press, 2012.

17. David, Richard. Typing Politics. New York: Oxford University Press, 2009.

18. Sunstein, Cass. Infotopia: How Many Minds Produce Knowledge. New York: Oxford University Press, 2001.

19. Praiser, Eli. The Filter Bubble: What the Internet Is Hiding from You. New York: Penguin Press, 2011.

20. Jenkins, Henry. Convergence Culture: Where Old and New Media Collide. New York: New York University Press, 2006.

21. Dabashi, Hamid. Iran, the Green Movement and the USA: The Fox and the Paradox. London: Zed Books, 2010, p. 54.

22. Kalantary, Afsaneh. "The Spirit of Carnival in the Iranian Presidential Election Campaign of 2009." Available online: http:/ / societyforiranianstudies.org/node/294 (accessed on 14 November 2016).

23. Gheissari, Ali, and Vali Nasr. Democracy in Iran: History and the Quest for Liberty. Oxford: Oxford University Press, 2006, p. 132.

24. Peterson, Scott. Let the Swords Encircle Me: Iran-A Journey Behind the Headlines. London: Simon \& Schuster, 2011, p. 487.

25. Mitchell, W. J. T., Bernard E. Harcourt, and Michael Taussig. Occupy: Three Inquires in Disobedience. Chicago and London: The University of Chicago Press, 2013, p. 53.

26. Akhavan, Niki. Electronic Iran: The Cultural Politics of an Online Evolution. New Brunswick: Rutgers University Press, 2013.

27. Sadeghi Esfahlani, Mohammad. "The Politics and Anti-Politics of Facebook in Context of the Iranian 2009 Presidential Elections and Beyond." In Social Media in Iran: Politics and Society after 2009. Edited by David Faris and Babak Rahimi. Albany: State University Press of New York, 2015, p. 144.

28. Gheytanchi, Elham, and Babak Rahimi. "Iran's Reformists and Activists: Internet Exploiters." Middle East Policy Journal 15 (2008): 45-59.

29. Rahimi, Babak. "Agonistic Social Media: Cyberspace in the Formation of Dissent and Consolidation of State Power in Postelection Iran." The Communication Review 14 (2011): 158-78. 
30. Fathi, Nazila. “Opposition Hardens Line inside Iran.” New York Times, 28 February 2010. Available online: http://www.nytimes.com/2010/02/03/world/middleeast/03iran.html?scp=2\&sq=moussavi\&st= cse\&_r=0 (accessed on 14 November 2016).

31. Mcluhan, Marshall. The Medium Is the Message: An Inventory of Effects. Corte Madera: Gingko Press, 2001.

32. McAdam, Doug, John D. McCarthy, and Mayer Zald, eds. Comparative Perspective on Social Movement: Political Opportunities, Mobilizing Structures, and Cultural Framings. Cambridge and New York: Cambridge University Press, 1996.

33. Fahlenbrach, Kathrin, Erling Sivertsen, and Rolf Werenskjold, eds. Media and Revolt: Strategies and Performances from the 1960s to the Present. New York: Berghahan Books, 2014.

34. Tavaana Tech. "Darbareh Vahid Online; Shahrvand konjkave internet." Available online: https://tech. tavaana.org/fa/Vahid-Online (accessed on 18 October 2013).

35. Vahid Online. "Si Salegi, khoshi-ha va hasrat-hayeh online va offline." Available online: http://vahid-online. net (accessed on 14 November 2016).

36. Yahyanenjad, Mehdi, and Elham Gheytanchi. "Social Media, Dissent, and Iran's Green Movement." In Liberation Technology: Social Media and the Struggle for Democracy. Edited by Larry Diamond and Marc F. Plattner. Baltimore: The Johns Hopkins University Press, 2012, p. 146.

37. Conley, Tara L. "From \#RenishaMcBride to \#RememberRenisha: Locating Our Stories and Finding Justice." Feminist Media Studies 14 (2014): 1111-13.

38. Mackey, Robert. "After Long Night of Counting, Post-Election Celebrations in Iran." Available online: http:/ / thelede.blogs.nytimes.com/2013/06/15/after-long-night-of-counting-post-election-celebrationsin-iran/?_r=0 (accessed on 15 June 2013).

39. It is likely that the number of users in 2013 was less than 20 million, nevertheless Telegram remained the most popular social media app during 2013 elections. Dehghan, Saed Kamali. “Telegram: The instant message app freeing up Iranians' conversations." Available online: https:/ /www.theguardian.com/world/2016/feb/ 08/telegram-the-instant-messaging-app-freeing-up-iranians-conversations (accessed on 8 February 2016).

40. Villi, Mikko. "Visual Mobile Communication on the Internet: Patterns in Publishing and Messaging Camera Phone Photographs." In Mobile Media Practices, Presence and Politics: The Challenge of Being Seamlessly Mobile. Edited by Kathleen M. Cumiskey and Larissa Hjorth. New York and London: Routledge, 2013, pp. $214-28$.

(C) 2016 by the author; licensee MDPI, Basel, Switzerland. This article is an open access article distributed under the terms and conditions of the Creative Commons Attribution (CC-BY) license (http://creativecommons.org/licenses/by/4.0/). 